\title{
Simulation of the E1 and E6 Galileo Signals using SIMULINK
}

\author{
M.Elhawary \\ National Institute for \\ Standards \\ Giza, Egypt
}

\author{
G.Gomah \\ National Institute for \\ Standards \\ Giza, Egypt
}

\author{
A.Zekry \\ Ain Shams \\ University \\ Cairo, Egypt
}

\author{
I. Hafez \\ Ain Shams \\ University \\ Cairo, Egypt
}

\begin{abstract}
For the time being there are many Global Navigation Satellite Systems(GNSSs) in the world that have both navigation and timing capabilities. Most of the GNSSs share a great part in the design architecture of both the transmitter and receiver. So, it became necessary to use flexible tools in the system design to facilitate both the modernization plans of the current systems and the launching of new systems. This article introduces a new look for the simulation of Galileo signals using a Graphical programming language; which is SIMULINK.
\end{abstract}

\section{Keywords}

Global Navigation Satellite System (GNSS), Galileo system, BOC modulation, $\mathrm{CBOC}$ modulation, system design.

\section{INTRODUCTION}

There are many GNSS systems in the world. The main tasks of such systems are navigation and timing. They share an almost similar design architecture for both the transmitter and receiver. Galileo is the European independent (GNSS), providing highly accurate and guaranteed global positioning and timing services under civilian control. It is inter-operable with the American GNSS, which is the Global Positioning system (GPS), and the Russian GNSS, which is the GLONASS. By offering dual frequencies as standard, Galileo will deliver real-time positioning accuracy down to the meter range [1]. It will guarantee availability of the service under all the most extreme circumstances and will inform users within seconds of any satellite failure. This makes it suitable for safety-critical applications such as guiding cars, running trains and landing aircraft.

The successful design and implementation of the Galileo receiver strongly depends on to which extent we could simulate the Galileo signals to test the functionality of the receiver. During the design stage of the receiver it is preferable to use simulated signals than real signals to be able to control the properties of the received signal. Moreover, the Interface Control Document (ICD) that defines the main requirements of the Galileo system recommends introducing flexible designs because the system is still under development and is subject to modifications.

During the last years a lot of efforts have been exerted to design and implement Galileo signals simulator. The Software Defined Radio (SDR) technique was used as a tool in the implementation using text based programming languages like VHDL and C-language. This paper introduces the simulation of the European Global Navigation Satellite System (Galileo) transmitter signals through a graphical programming language, which is SIMULINK, with the same efficiency as the text based programming languages. Using a graphical programming language makes every part in the transmitter architecture very clear and easier to understand, follow and modify. This makes the designer consumes less time in developing the system. This paper is a continuation to the trend that has been initiated by G.Gomah and A.Zekry that fruited two papers titled "Implementation of a complete GPS receiver using simulink " and "Implementation of a Complete GPS Receiver on the C6713 DSP through Simulink Receiver" [2][3]. They simulated and implemented a complete GPS receiver using SIMULINK. The GPS receiver was simulated before by Kai Bore and Dennis Akos using a text programming language; which was the VHDL language [4][5].

At 2009, both R.C.Pedrós and M.O'Droma have introduced the simulation of Galileo signals using text programming language; which is the Matlab language (m-files). Their work was included in a Master of Science (MSc) thesis titled "GALILIEO SIGNAL GENERATION SIMULATION ANALYSIS" at Department of Computer and Electronic Engineering, University of Limerick [6]. In this article the mfiles that are written in the previous Master thesis are converted to Simulink models with the same efficiency after modifying the algorithm to conform with the Graphical User Interface (GUI) environment and following the latest issue of "European GNSS (Galileo) Open Service Signal In Space Interface Control Document (OS SIS ICD, Issue 1.1, September 2010)" [7]. The models introduced in this paper are for the E1 and E6 signals.

This article adds a step on the route toward a clear, easy and transparent simulation of Galileo transmitter implemented with the SDR technology.

\section{THE E1 SIGNAL SIMULATOR}

Galileo E1-signal comprises two components E1-B and E1-C. It is transmitted in the frequency band $1559-1610 \mathrm{MHz}$ allocated to Radio Navigation Satellite System (RNSS) and Aeronautical Radio Navigation Service (ARNS) on a worldwide co-primary basis (ITU-R Radio Regulations). Its carrier frequency at $1575.42 \mathrm{MHz}$ with $24.552 \mathrm{MHz}$ bandwidth. The signal components E1-B and E1-C are datacomponent and pilot component respectively. The E1-signal provides the I/NAV message and supports Safety of Life service, Galileo system integrity and Open Service. Table (1) shows the technical specifications of the E1 signal [7] [8]. 
Table 1. Galileo E1 signal technical characteristics

\begin{tabular}{|c|c|c|}
\hline Component & $\begin{array}{c}\text { Component B } \\
{[\text { E1-B] }}\end{array}$ & $\begin{array}{c}\text { Component C } \\
\text { [E1-C] }\end{array}$ \\
\hline Service Name & \multicolumn{2}{|c|}{$\begin{array}{c}\text { Open Service (OS) } \\
\text { Commercial Service (CS) } \\
\text { Safety of Life (SoL) Service }\end{array}$} \\
\hline Carrier Frequancy & \multicolumn{2}{|c|}{$1575.42 \mathrm{MHz}$} \\
\hline Bandwidth & \multicolumn{2}{|c|}{$24.552 \mathrm{MHz}$} \\
\hline Frequency Band & \multicolumn{2}{|c|}{ E1 } \\
\hline Access Technique & \multicolumn{2}{|c|}{ CDMA } \\
\hline $\begin{array}{l}\text { Spreading } \\
\text { Modulation }\end{array}$ & \multicolumn{2}{|c|}{$\operatorname{CBOC}(6,1,1 / 11)$} \\
\hline $\begin{array}{l}\text { Sub-Carrier } \\
\text { Frequency }\end{array}$ & \multicolumn{2}{|c|}{$\begin{array}{c}1.024 \mathrm{MHz} \text { and } 6.138 \mathrm{MHz} \text {, (Two } \\
\text { Sub-Carrier) }\end{array}$} \\
\hline Chip rate & \multicolumn{2}{|c|}{ 1.023 Mcps } \\
\hline Signal Type & Data & Pilot \\
\hline $\begin{array}{l}\text { Primary PRN } \\
\text { code length }\end{array}$ & \multicolumn{2}{|c|}{4092 chips } \\
\hline Code Family & \multicolumn{2}{|c|}{ Memory codes } \\
\hline $\begin{array}{l}\text { Secondary PRN } \\
\text { code length }\end{array}$ & N/A & 25 chips \\
\hline $\begin{array}{l}\text { Tiered code } \\
\text { period }\end{array}$ & $4 \mathrm{~ms}$ & $100 \mathrm{~ms}$ \\
\hline Symbol rate & $250 \mathrm{Sps}$ & N/A \\
\hline
\end{tabular}

The E1 Open Service Data channel $\left(e_{E 1-B}\right)$ is generated from the integrity navigation data stream $\left(D_{E 1-B}\right)$ and the ranging code $\left(C_{E 1-B}\right)$, which are modulated with the sub-carriers $S C_{E 1-B O C(1,1)}$ (subcarrier with $\left.\operatorname{BOC}(1,1)\right)$ and $S C_{E 1}$ $-B O C(6,1)$ (subcarrier with $\operatorname{BOC}(6,1))$. Equation (1) shows the generation of the $e_{E 1-B}$ signal.

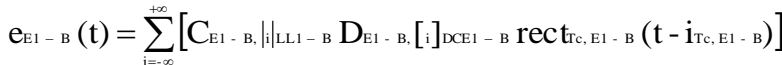

Where:-

$\mathrm{e}_{\mathrm{E} 1-\mathrm{B}}(\mathrm{t})$ is the Binary NRZ modulated navigation signal of component $\mathrm{B}$ including ranging code, sub-carrier and navigation message data $\left(e_{E 1-B}(t)=c_{E 1-B}(t) s_{E 1-B}(t) D_{E 1-B}(t)\right)$.

$\mathrm{C}_{\mathrm{E} 1-\mathrm{B}}(\mathrm{t})$ is the Ranging code of component E1-B.

$\mathrm{D}_{\mathrm{E} 1-\mathrm{B}}(\mathrm{t})$ is the Integrity Navigation (I/NAV) data stream of component $\mathrm{B}$.

$\operatorname{rect}_{T}(t)=\left\{\begin{array}{lr}1 & \text { at } 0<\mathrm{t}<\mathrm{T} \\ 0 & \text { elsewhere }\end{array}\right.$

$\mathrm{L}_{\mathrm{L} 1-\mathrm{B}}$ is the Ranging code repetition period of component $\mathrm{C}$ in chips.

$|\mathrm{i}|_{\text {L L1-B }}$ is the i modulo L.

$[\mathrm{i}]_{\text {DCE1-B }}$ is the Integer part of $\mathrm{i} / \mathrm{DC}_{\mathrm{E1}-\mathrm{B}}$.

$\mathrm{T}_{\mathrm{c}, \mathrm{El}-\mathrm{B}}$ is the Ranging code chip length of component $\mathrm{B}$ in [second].
The E1 Open Service Pilot component $\left(\mathrm{e}_{\mathrm{E} 1-\mathrm{C}}\right)$ is generated from the ranging code $\left(\mathrm{C}_{\mathrm{E} 1-\mathrm{C}}\right)$ including its secondary code that is modulated with the sub carriers $\mathrm{SC}_{\mathrm{E} 1-\mathrm{BOC}(1,1)}\left(\mathrm{sc}_{\mathrm{E} 1 \mathrm{C}, \mathrm{a}}\right)$ and $\mathrm{SC}_{\mathrm{E} 1-\mathrm{BOC}(6,1)}\left(\mathrm{sc}_{\mathrm{E} 1-\mathrm{C}, \mathrm{b}}\right)$. Equation (2) shows the generation of the $e_{E 1-C}$ signal. Figure (1) shows the modulation scheme of the E1 signal while Figure (2) Shows the Simulink model that represent $\mathrm{S}_{\mathrm{E} 1}$ signal using $\mathrm{CBOC}$ Modulation and the Power Spectral Density (PSD) of the resultant generated signal.

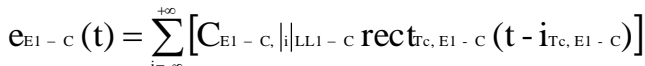

Where:-

$\mathrm{e}_{E 1-C}(\mathrm{t})$ is the Binary NRZ modulated navigation signal of component $\mathrm{C}$ including ranging code and sub-carrier $\left(\mathrm{e}_{\mathrm{E} 1-\mathrm{C}}(\mathrm{t})=\right.$ $\left.\mathrm{c}_{\mathrm{E} 1-\mathrm{C}}(\mathrm{t}) \mathrm{sc}_{\mathrm{E} 1-\mathrm{C}}(\mathrm{t})\right)$.

$\mathrm{C}_{\mathrm{E} 1-\mathrm{C}}(\mathrm{t})$ is the Ranging code of component E1-C.

$\operatorname{rect}_{\mathrm{T}}(\mathrm{t})$ is the function "Rectangle" which is equal to 1 for $0<\mathrm{t}<\mathrm{T}$ and equal 0 elsewhere.

$\mathrm{L}_{\mathrm{Ll}-\mathrm{C}}$ is the Ranging code repetition period of component $\mathrm{C}$ in [chips].

| $\left.\mathrm{i}\right|_{\text {L L1-B }}$ is the i modulo L.

$\mathrm{T}_{\mathrm{c} \text { E1-C }}$ is the Ranging code chip length of component $\mathrm{C}$ in [second].

(CB and CC: the ranging code of components $\mathrm{B}$ and $\mathrm{C}$ respectively, DCB: Data of component $\mathrm{B}, \mathrm{scB}$ and $\mathrm{scC}$ : subcarrier of components $\mathrm{B}$ and $\mathrm{C}$ respectively).

Both the pilot and data components are modulated onto the same carrier component, with a power sharing of $50 \%$. The E1 CBOC signal is generated according to equation 3 , with the binary signal components $\mathrm{e}_{\mathrm{E} 1-\mathrm{B}}(\mathrm{t})$ and $\mathrm{e}_{\mathrm{E} 1-\mathrm{C}}(\mathrm{t})$.

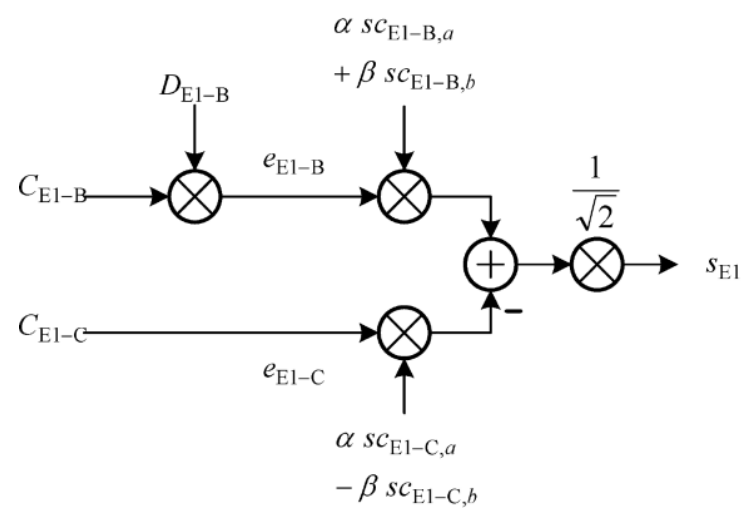

Fig 1: Modulation Scheme for the E1 CBOC Signal 


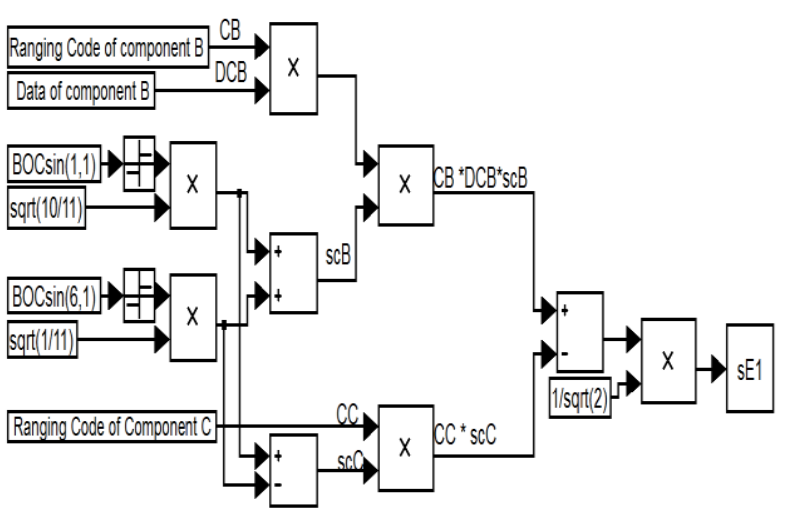

Fig 2: Simulink model that represents the $S_{E 1}$ signal using CBOC Modulation

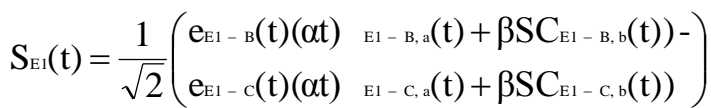

$\mathrm{SC}_{\mathrm{x}}(\mathrm{t})=\operatorname{sign}\left(\sin \left(2 \pi \mathrm{R}_{\mathrm{x}} \mathrm{t}\right)\right), \alpha=\sqrt{\frac{10}{11}}$ and $\beta=\sqrt{\frac{1}{11}}$

Where :-

$\mathbf{s c}_{\mathrm{E} 1-\mathrm{B}, \mathrm{a}}(\mathbf{t})$ and $\mathbf{s c}_{\mathrm{E} 1-\mathrm{B}, \mathrm{b}}(\mathbf{t})$ are the sub-carrier of component B.

$\mathbf{s c}_{\mathrm{E} 1-\mathrm{C}, \mathrm{a}}(\mathbf{t})$ and $\mathbf{s c}_{\mathrm{E} 1-\mathrm{C}, \mathrm{b}}(\mathbf{t})$ are the sub-carrier of component $\mathrm{C}$.

$\mathrm{R}_{\mathrm{s}, \mathrm{x}}$ are the sub-carrier frequency in $\mathrm{Hz}$.

The parameters $\alpha$ and $\beta$ are chosen such that the combined power of the $\mathrm{sc}_{\mathrm{E} 1-\mathrm{B}}$, and $\mathrm{sc}_{\mathrm{E} 1-\mathrm{C}}$ sub carrier components equals to $1 / 11$ of the total power of $\left(\mathrm{e}_{\mathrm{E} 1-\mathrm{B}}+\mathrm{e}_{\mathrm{E} 1-\mathrm{C}}\right)$.

\subsection{The generation of the navigation data}

The navigation data of the E1 signal is generated by using random values according to the Simulink model shown in figure 3. The symbol rate of component B is $250 \mathrm{Sps}$. These random values are generated by using the "randn" function that generates Normally distributed pseudorandom numbers. The generated two numbers are converted to \pm 1 to get binary NRZ values. Then, the two bits are converted into frame that is repeated/ oversampled 368280 times, according to equation (4), to reach the length of the ranging code of component $\mathrm{B}$.

$\frac{\text { Sampling frequancy }(\mathrm{Hz})}{\text { Symbol rate of component B }(\mathrm{Sps})}=\frac{90 \times 1.023 \times 10^{6}}{250}=368280$

The generated random data of component $\mathrm{B}$ is shown in figures (4)

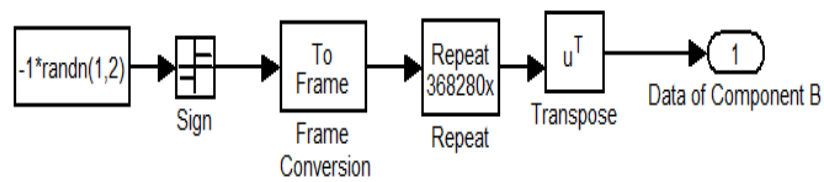

Fig 3: Simulink model that generate random data stream of component $B$

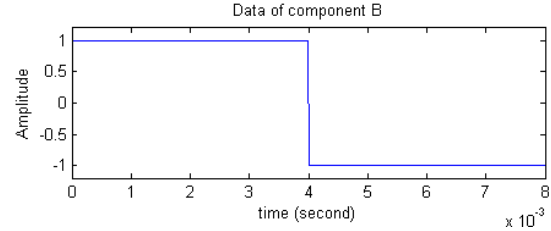

Fig 4: Generated random data of component B

\subsection{Ranging codes}

In our design of E1 signal we used a sampling frequency of $92.07 \mathrm{MHz}(90 \mathrm{fo}=90 \times 1.023 \mathrm{MHz})$. Component B $(\mathrm{E} 1-\mathrm{B})$ has only a primary code with 4092 chips, chipping rate of $1.023 \mathrm{Mcps}$ and $4 \mathrm{~ms}$ repetition rate. The 4092 chips are stored in memory then they are converted into frame that is repeated 90 times using matrix Concatenation. The $2 \mathrm{D}$ matrix is then converted into $1 \mathrm{D}$ vector that was converted from Unipolar to bipolar to get Binary NRZ ranging code. The simulink model and the generated ranging code of component $\mathrm{B}$ are shown in figures (5) and (6) respectively.

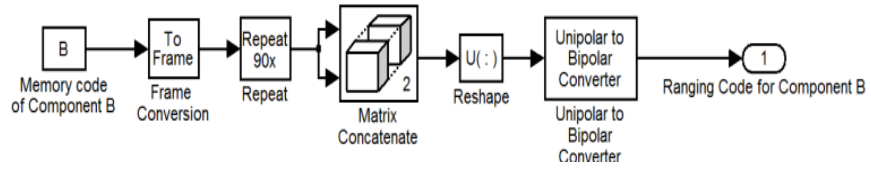

Fig 5: Simulink model that represent the ranging code of component $B$.

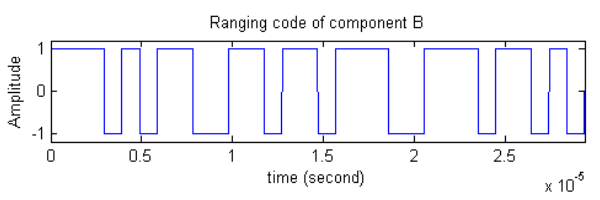

Fig 6: Generated Ranging code of component B

For component $\mathrm{C}$ (E1-C), the ranging code consists of two codes: primary code and secondary code. The primary code and secondary code are memory codes [3]. Primary code has 4092 chips and duration of $4 \mathrm{~ms}$. The secondary code has 25 chips and is used in modulating the 4092 chips of primary code. Each 4092 chips of primary code are Xord with one chip of the secondary code to give 25 chips $\times 4092$ chips. The spreading code of component $\mathrm{C}$ has a repetition rate of 100 ms. Figure (7) shows the Simulink model for generating the ranging code of component $\mathrm{C}$ and figure (8) shows the generated code.

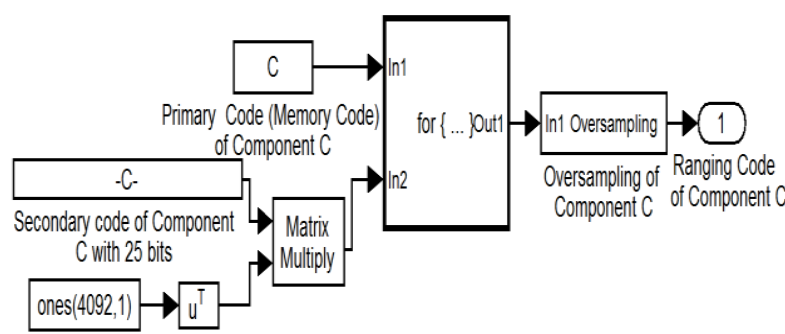

Fig 7 : Simulink model for generating the ranging code of component $\mathbf{C}$. 


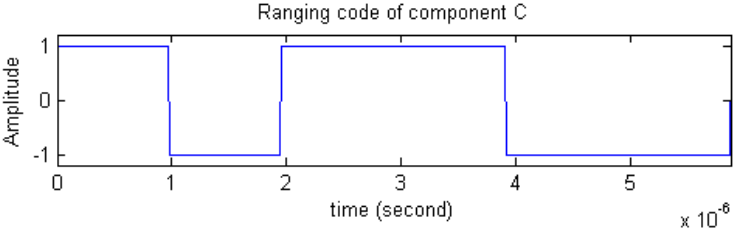

Fig 8: Generated Ranging code of component $C$.

\subsection{Binary Offset Carrier (BOC) modulation}

Galileo signals are modulated by a new modulation technique; which is called Binary Offset Carrier (BOC) modulation. BOC modulation is designed to modernize GPS and Galileo Systems to facilitate adding another signals that have the same carrier frequency into the radio frequency bands without interfering with the other signals. The advantages of BOC modulation are: improve the traditional GNSS signals properties for better resistance to multipath and interferences of all kinds of noise and provides spectral isolation between signals that have the same carrier frequency [8]. A BOCmodulated signal consists of a sinusoidal carrier, square wave sub-carrier (BOCsin and BOCcos), PN code and a data sequence. The BOC signal is the product, in the time domain, of all of these components. Equations (5) and (6) identify the BOCsin and BOCcos respectively:

$$
\begin{aligned}
& \text { BOCsin }: \operatorname{sc}(t)=\operatorname{sign}(\sin (2 \pi F s t)) \\
& \text { BOCcos }: \operatorname{sc}(t)=\operatorname{sign}(\cos (2 \pi F s t))
\end{aligned}
$$

Where Fs is the sub-carrier frequency

BOC modulation is identified as $\operatorname{BOC}(m, n)$. The two independent parameters $\mathrm{m}$ and $\mathrm{n}$ are used to concentrate the signal power in specific parts of the spectrum to reduce interference with other signals. $\mathrm{m}$ and $\mathrm{n}$ are identified as:

$\mathrm{m}=\frac{\mathrm{F}_{\mathrm{s}}}{\mathrm{F}_{\mathrm{o}}}, \mathrm{n}=\frac{\mathrm{F}_{\mathrm{c}}}{\mathrm{F}_{\mathrm{o}}}$

Where:-

$\mathrm{F}_{\mathrm{s}}$ is the sub-carrier frequency in $\mathrm{MHz}$.

$F_{c}$ is the chipping rate in Mcps.

$\mathrm{F}_{\mathrm{o}}$ is the reference frequency $\left(\mathrm{F}_{\mathrm{o}}=1.023 \mathrm{MHz}\right.$ and is generated by the atomic clock on-board of Galileo satellites).

Components $\mathrm{B}$ and $\mathrm{C}$ are modulated by Composite $\mathrm{BOC}$ (CBOC $(6,1,1 / 11))$ modulation. CBOC modulation combines $\operatorname{BOC}(1,1)$ and $\operatorname{BOC}(6,1)$. CBOC modulation is the result of multiplexing a narrow band signal, BOC $(1,1)$, which has a sub-carrier frequency of $1.023 \mathrm{MHz}$ and chipping rate of $1.023 \mathrm{Mcps}$, with a wide band signal BOC $(6,1)$ that has a sub-carrier frequency of $6.138 \mathrm{MHz}$ and chipping rate 1.023 Mcps. The normalized power spectral density of $\operatorname{CBOC}(6,1,1 / 11)$ is given by equation (7):

$\mathrm{G}_{\mathrm{Cвос(6,1,1/1)}}(\mathrm{f})=\frac{10}{11} \mathrm{G}_{\mathrm{Bос}(1,1)}(\mathrm{f})+\frac{1}{11} \mathrm{G}_{\mathrm{Bос}(6,1)}(\mathrm{f})$

Where $\mathrm{G}_{\mathrm{CBOC}(\mathrm{m}, \mathrm{n})}(\mathrm{f})$ is the unit PSD of sine phased BOC modulation.
So $1 / 11$ of the power is allocated on the high frequency Component (BOC $(6,1))$.

CBOC modulation for components $\mathrm{B}$ and $\mathrm{C}$ can be illustrated by equations (8) and (9) respectively:

$$
\begin{aligned}
& \operatorname{scB}(t)=\alpha \operatorname{sc}(t)_{\text {вос }(1,1)}+\beta \operatorname{sc}(t)_{\text {вос }(6,1)} \\
& \operatorname{scC}(t)=\alpha \operatorname{sc}(t)_{\text {вос }(1,1)-\beta \operatorname{sc}(t)_{\text {вос }(6,1)}}
\end{aligned}
$$

$$
\text { Where : } \alpha=\sqrt{\frac{1}{10}} \text { and } \beta=\sqrt{\frac{10}{11}}
$$

Figure (9) and figure (10) show the generated CBOC subcarrier for $\mathrm{scB}(\mathrm{t})$ and $\mathrm{scC}(\mathrm{t})$ respectively using Simulink.

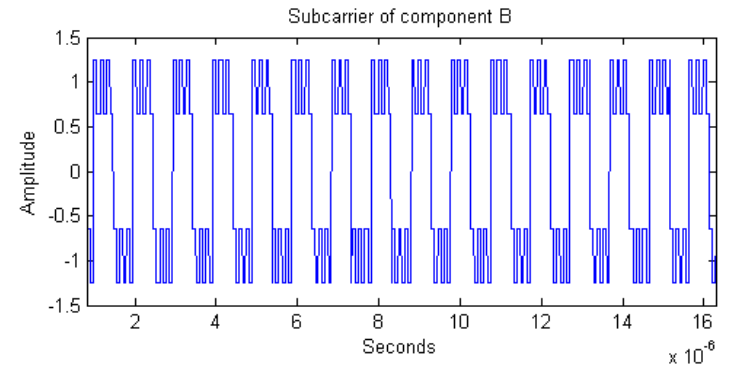

Fig 9: CBOC Subcarrier of component $B$ with $B O C(1,1)$ and $\operatorname{BOC}(6,1)$

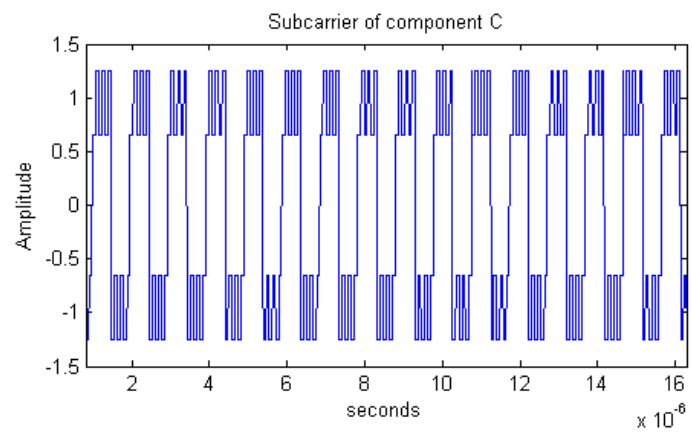

Fig 10: CBOC Subcarrier of component $C$ with $\operatorname{BOC}(1,1)$ and $\operatorname{BOC}(6,1)$

BOC modulation splits the spectrum into two symmetric main lobes centered at $\pm \mathrm{fs} \mathrm{MHz}$ (subcarrier frequency) around the carrier frequency. The generated PSD of SE1 is shown in figure (11). Figure 12 shows the transmitted SE1 signal with the generated waveforms.

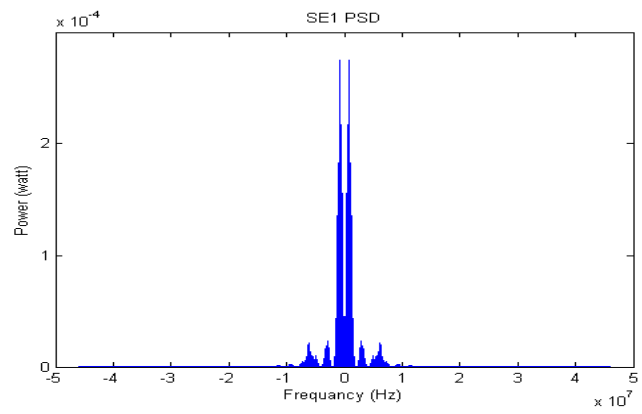

Fig 11: PSD of SE1 signal 


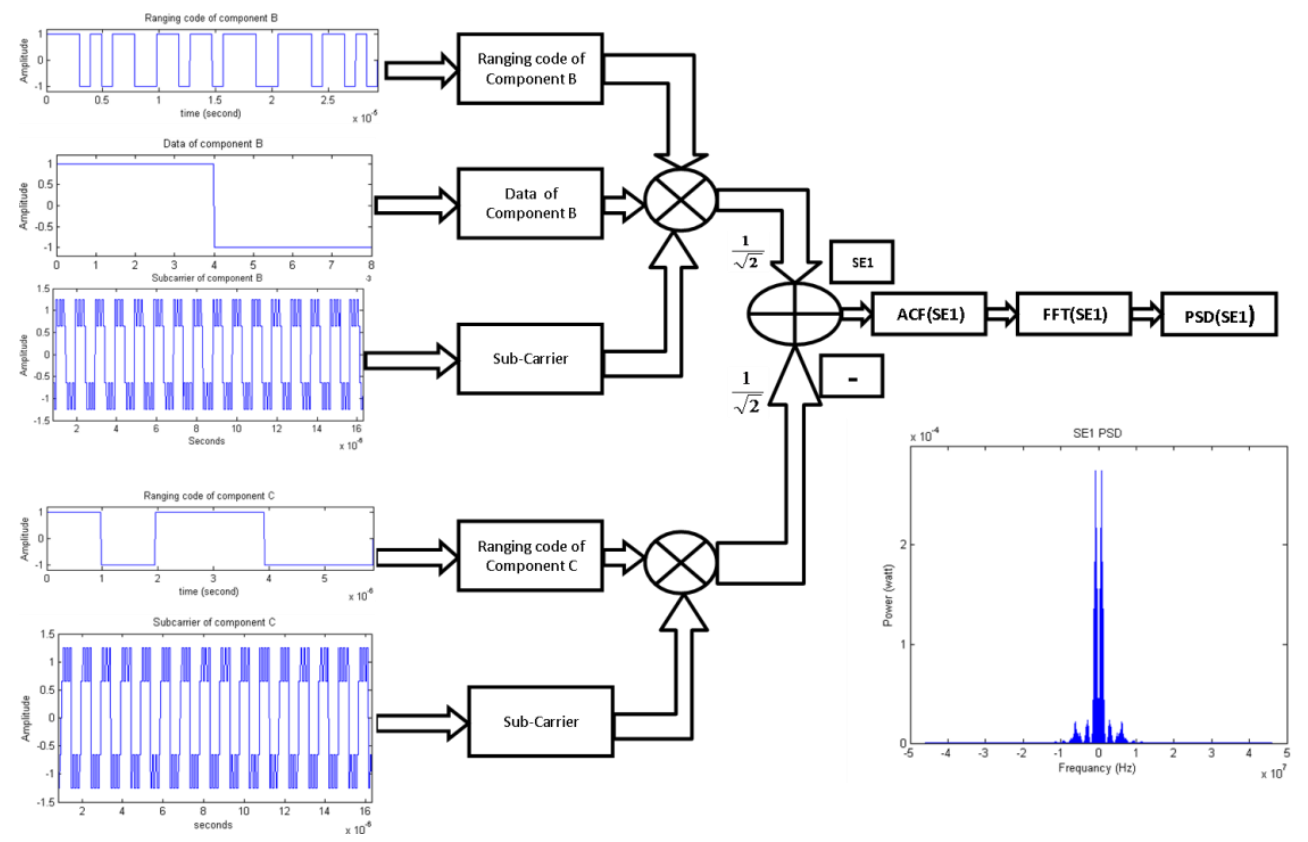

Fig 12: The SE1 signal with generated data and ranging code with PSD

\section{E6 SIGNAL SIMULATOR}

The technical specifications of the E6 signal are summarized in table 2 [7] [8].

Table 2. The technical specification of Galileo E6 signal

\begin{tabular}{|c|c|c|}
\hline Component & $\begin{array}{c}\text { Component B } \\
\text { [E1-B] }\end{array}$ & $\begin{array}{c}\text { Component C } \\
\text { [E1-C] }\end{array}$ \\
\hline Service Name & Commercial Service (CS) \\
\hline Carrier Frequancy & \multicolumn{2}{|c|}{$1278.75 \mathrm{MHz}$} \\
\hline Bandwidth & \multicolumn{2}{|c|}{$40.920 \mathrm{MHz}$} \\
\hline Frequency Band & \multicolumn{2}{|c|}{ E6 } \\
\hline Access Technique & \multicolumn{2}{|c|}{ CDMA } \\
\hline $\begin{array}{c}\text { Spreading } \\
\text { Modulation }\end{array}$ & \multicolumn{2}{|c|}{ BPSK(5) } \\
\hline $\begin{array}{c}\text { Sub-Carrier } \\
\text { Frequency }\end{array}$ & \multicolumn{2}{|c|}{ N/A } \\
\hline Chip rate & \multicolumn{2}{|c|}{$5115 \mathrm{Mcps}$} \\
\hline Signal Type & Data & Pilot \\
\hline $\begin{array}{c}\text { Primary PRN } \\
\text { code length }\end{array}$ & \multicolumn{2}{|c|}{5115 chips } \\
\hline Code Family & \multicolumn{2}{|c|}{ LFSR chips } \\
\hline $\begin{array}{c}\text { Secondary PRN } \\
\text { code length }\end{array}$ & N/A & N/A \\
\hline Symbol rate & 1000 Sps & \multicolumn{2}{|c|}{50 componts: } \\
\hline
\end{tabular}

Galileo E6 signal consists of the following two components:

- Data component $\left(\mathrm{e}_{\mathrm{E} 6-\mathrm{B}}\right)$, which is dedicated for Commercial Service, is generated from the modulo2 addition of the $\mathrm{C} / \mathrm{NAV}$ message data stream $\mathrm{D}_{\mathrm{E} 6-\mathrm{B}}$ and the ranging code $\mathrm{C}_{\mathrm{E} 6-\mathrm{B}}$ that has chipping rate of 5.115 Mcps.
- Pilot component ( $\mathrm{e}_{\mathrm{E} 6-\mathrm{C}}$ ) that is dedicated for Commercial Service (CS) and is generated from the ranging code $\left(\mathrm{C}_{\mathrm{E} 6-\mathrm{C}}\right)$; which has chipping rate of 5.115 Mcps.

The E6 signal is generated by combining components B and C according to equation (10) and as shown in figure (13). Figure (14) shows the Simulink model for the E6 signal. In the following sections the method of generating the navigation data and ranging code will be mentioned.

$\mathrm{S}_{\mathrm{E} 6}(\mathrm{t})=\frac{1}{\sqrt{2}}\left[\mathrm{e}_{\mathrm{E} 6-\mathrm{B}}(\mathrm{t})-\mathrm{e}_{\mathrm{E} 6-\mathrm{C}}(\mathrm{t})\right](10)$

Such that,

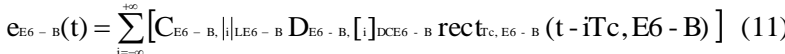

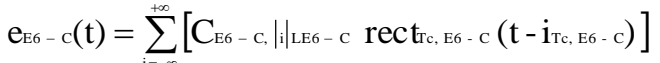

Where:

$\mathrm{D}_{\mathrm{E} 6-\mathrm{B}}$ : is the $\mathrm{C} / \mathrm{NAV}$ Navigation data stream of component $\mathrm{B}$.

$\mathrm{C}_{\mathrm{E} 6-\mathrm{B}}$ : is the ranging code of component $\mathrm{B}$.

$\mathrm{C}_{\mathrm{E} 6-\mathrm{C}}$ :is the ranging code including its secondary code of component $\mathrm{C}$.

$\mathrm{e}_{\mathrm{E} 6-\mathrm{B}}(\mathrm{t})$ :is the Binary NRZ modulated navigation signal of component $\mathrm{B}$ including ranging code, sub-carrier and navigation message data. $\left(\mathrm{e}_{\mathrm{E} 6-\mathrm{B}}(\mathrm{t})=\mathrm{c}_{\mathrm{E} 6-\mathrm{B}}(\mathrm{t}) \mathrm{D}_{\mathrm{E} 6-\mathrm{B}}(\mathrm{t})\right)$.

$\operatorname{rect}_{T c}(t)$ : is the function "Rectangle" which is equal to 1 for $0<\mathrm{t}<\mathrm{T}$ and equal 0 elsewhere.

$[i]_{\text {DCE6-B }}$ : is the Integer part of $\mathrm{i} / \mathrm{DC}_{\mathrm{E} 1-\mathrm{B}}$.

$\mathrm{T}_{\mathrm{c}, \mathrm{E} 6-\mathrm{B}}$ : is the Ranging code chip length of component $\mathrm{B}$ in [seconds]. 
$\mathrm{e}_{\mathrm{E} 6-\mathrm{C}}(\mathrm{t})$ :is the Binary NRZ modulated navigation signal of component $\mathrm{C}$ including ranging code and sub-carrier. $\left(\mathrm{e}_{\mathrm{E} 6-\mathrm{C}} \mathrm{C}(\mathrm{t})=\right.$ $\left.\mathrm{c}_{\mathrm{E} 6-\mathrm{C}}(\mathrm{t})\right)$.

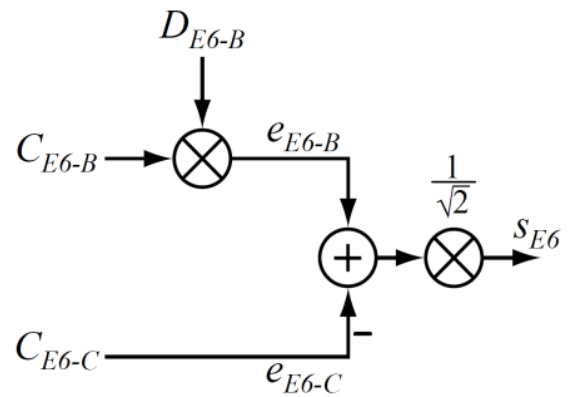

Fig 13: Modulation Scheme for the E6 Signal

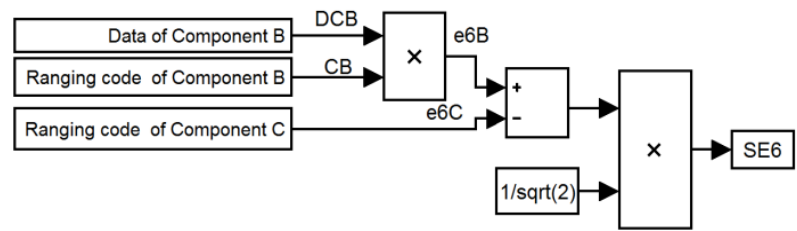

Fig 14: The E6 Simulink Model

( $\mathrm{CB}$ and e6C represent the ranging code of components $\mathrm{B}$ and $\mathrm{C}$ respectively, DCB is the Data of component $\mathrm{B}$ ).

\subsection{The generation of the navigation data}

The navigation data for the E6 signal is generated from ten supposed bits. The Simulink model for generating the navigation data stream of the E6 signal is shown in figure (15). The symbol rate of component B is 1000 Sps. So, every 10 bits (frame) are repeated (oversampled) 102300 times, according to equation (13). The generated data for the E6 signal is shown in figure (16).

$\frac{\text { Sampling frequancy }(\mathrm{Hz})}{\text { Symbol rate of component B (Sps) }}=\frac{100 \times 1.023 \times 10^{6}}{1000}=102300(13)$

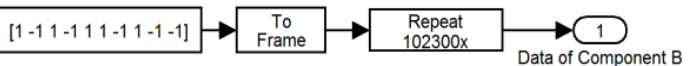

Fig 15:Simulink model that generate random data stream of component $B$

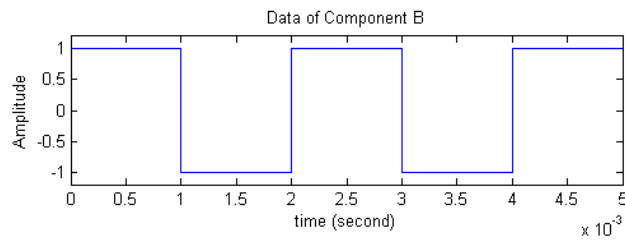

Figure 16: The generated random data of component $B$

\subsection{Ranging codes}

The Ranging codes for the E6 signal is implemented by a Linear Feedback Shift Register (LFSR). Table 3 and table 4 show the polynomials used with component B and C [9] [10] [11].
Table 3. The polynomials used with the LFSR of Component B

\begin{tabular}{|l|l|}
\hline \multicolumn{2}{|l|}{ E6-B code generators } \\
\hline E6-B code $(5115$ bits, $1 \mathrm{msec}, 13$ stage tiered code) \\
\hline Polynomial_1 & $\mathrm{X}^{13}+\mathrm{X}^{10}+\mathrm{X}^{8}+\mathrm{X}^{5}+1$ \\
\hline Initial state_1 & {$[1111111111111]$} \\
\hline Polynomial_2 & $\mathrm{X}^{13}+\mathrm{X}^{12}+\mathrm{X}^{11}+\mathrm{X}+1$ \\
\hline Initial state_2 & {$[0101011100000]$} \\
\hline
\end{tabular}

Table 4. The polynomials used with the LFSR of Component C

\begin{tabular}{|l|l|}
\hline \multicolumn{2}{|l|}{ E6-C code generators } \\
\hline E6-C code $(5115$ bits, $1 \mathrm{msec}, 14$ stage tiered code $)$ \\
\hline Polynomial_1 & $\mathrm{X}^{14}+\mathrm{X}^{11}+\mathrm{X}^{6}+\mathrm{X}+1$ \\
\hline Initial state_1 & {$[11111111111111]$} \\
\hline Polynomial_2 & $\mathrm{X}^{14}+\mathrm{X}^{8}+\mathrm{X}^{7}+\mathrm{X}^{4}+\mathrm{X}^{3}+\mathrm{X}^{2}+1$ \\
\hline Initial state_2 & {$[0101011100000]$} \\
\hline
\end{tabular}

The Ranging code of component B (data component) has only a primary code with 5115 chips and $1 \mathrm{~ms}$ repetitions rate. This primary code is generated by Xoring two sequences of the LFSR (Polynomial_1 xor Polynomial_2). After that, this sequence is converted from unipolar to bipolar to constitute a frame. Each frame is repeated 20 times. Using matrix Concatenation and reshaping, we reach a length of 1023000 , which is the length of the ranging code of component B. Figure (17) and figure (18) show the Simulink model for generating the ranging code of component $\mathrm{B}$ and the generated code respectively.

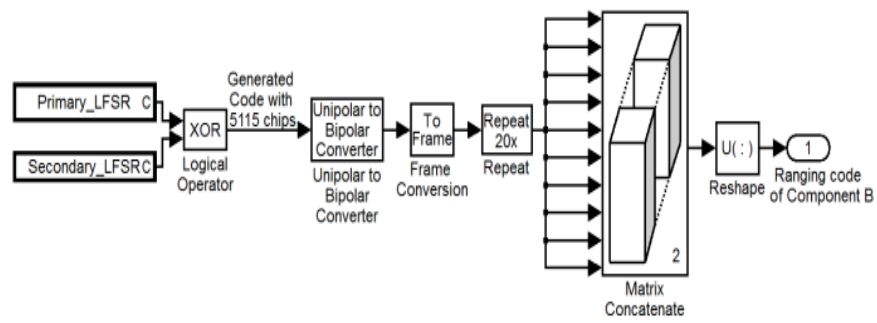

Fig 17: Simulink model of the ranging code of Component B

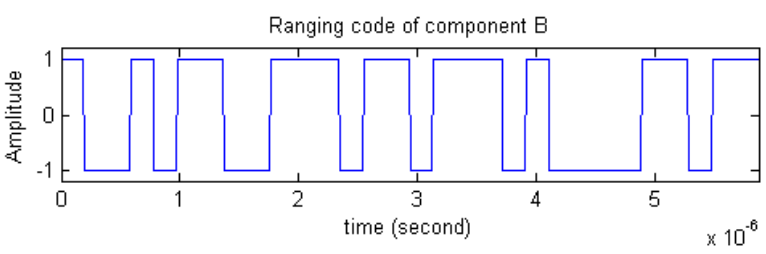

Fig 18: The generated ranging code for Component $B$

The ranging code of Component $\mathrm{C}$ (pilot component) consists of two codes: the primary code and secondary code. The primary code is a generated from LFSR with 5115 chips and $1 \mathrm{~ms}$ reputation rate and the secondary code is memory code that has 50 chips stored in memory. The ranging code of component $\mathrm{C}$ is generated by Xoring the primary code and the 
secondary code. Figure (19) shows the Simulink model for generating the ranging code of Component $\mathrm{C}$.

The primary code is generated by Xoring two sequences (Polynomial_1 xor Polynomial_2) as in table (4). Figure (20) shows the Simulink model for generating the primary code of Component $\mathrm{C}$.

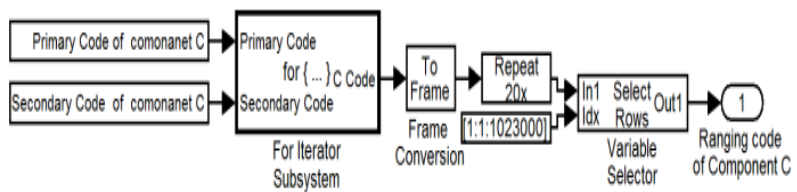

Fig 19: Simulink model for ranging code of Component $C$

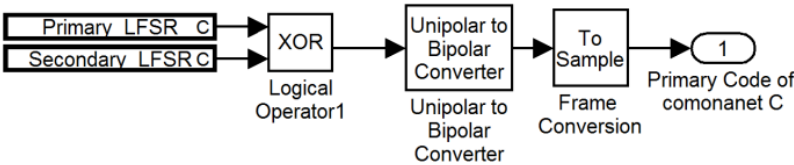

Fig 20: Simulink model for Primary code of Component C

The secondary code has 50 chips and is used in modulating the 5115 chips of the primary code. Figure (21) shows the Simulink model for generating the secondary code of Component $\mathrm{C}$

Each one chip of the secondary code is Xored with the 5115 chips of the primary code. After that this sequence is converted from unipolar to bipolar then converted into frame. Each frame is repeated 20 times after that a length of 1023000 is selected, which conforms to the length of the ranging code of component B. The generated ranging code is shown in figure (22).

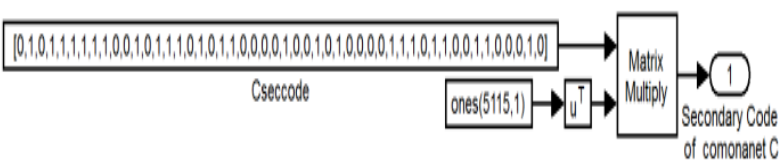

Fig 21: Simulink model for Secondary code of Component

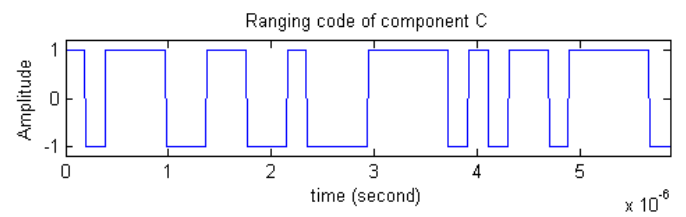

Fig 22: The generated ranging codes for Component $\mathrm{C}$

\subsection{Modulation of the E6 signal}

Both of the two components, B and C, are modulated by of $5 \times \mathrm{Fo}=5.115 \mathrm{Mcps}$. The sE6 signal is generated according to equation (10). The PSD of the sE6 signal has an only one main lobe, as shown in figure (23), due to using the BPSK modulation. Figure (24) shows the output of the Auto Correlation Function (ACF) of the sE6.

Figure 25 shows the transmitted SE6 signal with the generated waveforms (the ranging codes and navigation data stream).

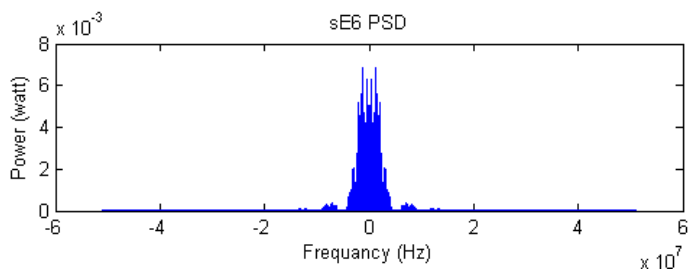

Fig 23: PSD of sE6 signal
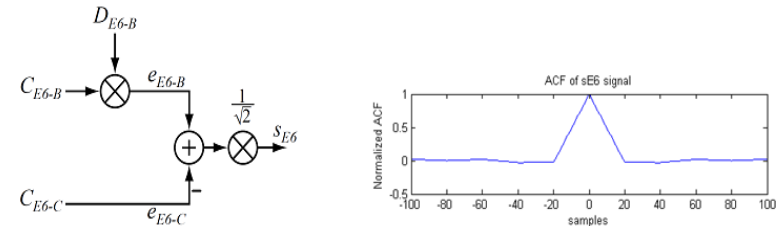

Fig 24: Normalized ACF BPSK(5) of components B and C at SE6

\section{CONCLUSION}

In general, graphical programming languages facilitate the system design because they make the relation between the system modeling, simulation and implementation very clear. Since the Galileo system is still under development and it is expected to encounter modifications, the transparent E1 and E6 signals simulator introduced in this article will facilitate both transmitter and receiver redesigns.

Moreover the simulated model has educational aims due to the transparency of the design and simulation. Also the introduced model can facilitate the system implementation. The implementation tools available in Simulink, such as the code composer studio, can be used in the implementation stage. Moreover, the design trend introduced in this article follow the recommendation of the ICD of Galileo system. Since the transmitter design of most of the GNSS systems is similar, then the simulation models introduced in this paper can be applied to other GNSS systems. Moreover, the design of the transmitter simulator will have a direct positive impact on the test and validation stages of the receiver.

Binary Phase Shift keying (BPSK) modulation with chip rate

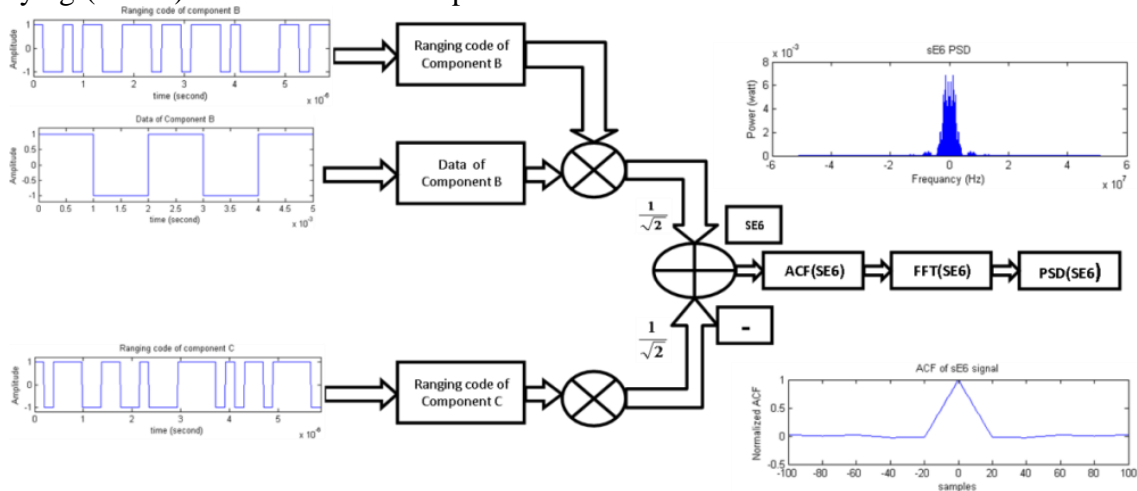

Fig 25: The SE6 signal with generated data and ranging code with PSD 


\section{REFERENCES}

[1] http://www.esa.int/Our_Activities/Navigation/The_future _Galileo/What_is_Galileo ,Last update: 15 January 2013.

[2] G. Hamza, A. Zekry, I. Motawie, "Implementation of a complete GPS receiver using simulink", Circuits and Systems Magazine, IEEE Volume: 9 , Issue: 4,2009 , Page(s): $43-51$.

[3] G. Gomah Hamza, A. Zekry, and M. N. Moustafa, "Implementation of a Complete GPS Receiver on the C6713 DSP through Simulink Receiver", Journal of Global Positioning Systems, Vol. 8, No. 1, 2009.

[4] K. Borre, D. Akos, "A Software-Defined GPS and Galileo Receiver; A Single-Frequency Approach", Birkhauser, New York, 2007.

[5] K. Borre, "The Galileo Signals With Emphasis on L1 OS", Danish GPS Center, Aalborg University, Power Electronics and Motion Control Conference, 2006.

[6] R.C.Pedrós and M.O'Droma, "GALILIEO SIGNAL GENERATION SIMULATION ANALYSIS", Department of Computer and Electronic Engineering, University of Limerick, 2009.
[7] European Space Agency /European GNSS Supervisory Authority. Galileo Open Service - Signal In Space Interface Control Document.OS SIS ICD, Issue 1.1, September 2010

[8] Jose-Angel Avila-Rodriguez,Guenter W.Hein,Stefan Wallner,Jean -Luc Issler,Lionel Ries,Laurent Lestarquit,Antoine de Latour,Jeremie Godet , Frederic Bastide,Tony Pratt.John Owen, "The MBOC Modulation:The Final Touch to the Galileo Frequancy and Signl Plan”, Inside GNSS, September/October 2007.

[9] Grace Xinngxin Gao,Jim Spilker,Todd Walter, and Per Enge Stanford University,CA,USA and Anthony R Pratt Orbstar Consultants,U.K "Code Generation Scheme and Property Analysis of Broadcast Galileo L1 and E6 signals".

[10] G. W. Hein, J. A. Avila-Rodriguez, and S. Wallner "The Galileo Code and Others”, Inside GNSS, September 2006.

[11] Grace Xingxin Gao, David S. De Lorenzo, Todd Walter and Per Enge, "Acquisition and Tracking of GIOVE-A Broadcast L1/E5/E6 signals and analysis of DME/TACAN Interference on Receiver Design", Stanford University. 